\title{
Safety and Tolerability of Transdermal Rotigotine in a Clinical Practice Cohort for 2 Years
}

\author{
Iria Rodriguez Constenla*, Antonio Pato Pato, Icíar Cimas Hernando, \\ José Ramón Lorenzo Gonzalez \\ Servicio de Neurología, Hospital Povisa, Vigo, Spain \\ Email: irodriguez@povisa.es, apatopato@gmail.com
}

Received 6 October 2014; revised 6 November 2014; accepted 21 November 2014

Copyright (C) 2014 by authors and Scientific Research Publishing Inc.

This work is licensed under the Creative Commons Attribution International License (CC BY). http://creativecommons.org/licenses/by/4.0/

(c) (i) Open Access

\begin{abstract}
Background: Parkinson's disease (PD) is a progressive neurodegenerative disease that occurs as a result of loss of dopaminergic neurons from the substantia nigra. Rotigotine is a non-ergolinic dopamine agonist available as a silicone-based transdermal patch for the treatment of PD. In the European Union, rotigotine transdermal patch is indicated for use as monotherapy in early idiopathic PD, or in combination with levodopa through the disease course to the late stages where motor complications with levodopa become an issue. Objective: To investigate the safety and tolerability of transdermal rotigotine, in patients with PD being treated during routine clinical practice for 2 years. Results: 114 patients were enrolled, and evaluated for adverse events over a 24month period. Adverse events occurred in 39 patients $(34.21 \%)$. 23 patients $(20.17 \%)$ reported application site reactions (dermatitis, erythema, itching), and 16 (14.03\%) had systemic adverse events. Sleep disorders were the most common problem; the others were hallucinations, depression, dizziness, and syncope. No patient experienced dyskinesia. Adverse events necessitated the discontinuation of rotigotine for application site reactions in fourteen patients $(12.28 \%)$ and 11 patients (9.64\%); reasons for discontinuation were systemic adverse events. Conclusion: Rotigotine is safe and well tolerated when used to treat PD in routine clinical practice.
\end{abstract}

\section{Keywords}

Rotigotine, Parkinson's Disease, Tolerability, Safety, Clinical Practice

\section{Introduction}

Parkinson's disease (PD) is a progressive neurodegenerative disease that occurs as a result of loss of dopaminer-

${ }^{*}$ Corresponding author.

How to cite this paper: Constenla, I.R., Pato, A.P., Hernando, I.C. and Gonzalez, J.R.L. (2014) Safety and Tolerability of Transdermal Rotigotine in a Clinical Practice Cohort for 2 Years. World Journal of Neuroscience, 4, 443-449.

http://dx.doi.org/10.4236/wjns.2014.45050 
gic neurons from the substantia nigra [1] [2]. Rotigotine (Neupro $\left.{ }^{\circledR}\right)$ is a non-ergolinic dopamine agonist available as a silicone-based transdermal patch for the treatment of PD. In the European Union, rotigotine transdermal patch is indicated for use as monotherapy in early idiopathic PD, in a maximal dose of $8 \mathrm{mg} / 24 \mathrm{~h}$ or in combination with levodopa through the disease course to the late stages where motor complications with levodopa become an issue until a maximum dose of $16 \mathrm{mg} / 24 \mathrm{~h}$ [3]. Patches are available which deliver nominal dosages of 2, 4, 6 or $8 \mathrm{mg}$ over a 24-hour period. The transdermal delivery system maintains a stable drug release profile allowing for a steady-state plasma concentration of rotigotine while the patch is applicated.

Multiple data of clinical trials indicate that rotigotine remains well tolerated over treatment periods of up to 6 years [4]-[7]. The objective of this study was to characterize the safety and tolerability of transdermal rotigotine in patients with PD being treated during routine management in a clinical hospital for up to 2 years.

\section{Methods}

\subsection{Study Design}

This prospective, observational, single-centre study was conducted at Hospital Povisa, Vigo, Spain from October 2010 to April 2012. Consecutive patients with an existing diagnosis of PD [8] who fulfilled the inclusion and exclusion criteria and who had a routine hospital medical visit during the recruitment period (2 years) were approached to participate in the study. Exclusion criteria were: secondary parkinsonism, dementia associated with PD, psychiatric complications or presence of intracranial lesions on neuroimaging tests. The study received approval from the local ethics committee (Comité de Ética Asistencial do Policlínico Vigo, S.A.) and all patients gave written informed consent. The study was conducted in accordance with the Declaration of Helsinki and Good Clinical Practice.

\subsection{Patients}

Patients had existing PD (Hoehn \& Yahr score of I - IV) and were being treated with rotigotine monotherapy or rotigotine in combination with other anti-PD medication. Drug dosages were at the discretion of the treating physician. Patients with uncontrolled cardiovascular risk factors or previous psychiatric illness were excluded, as were PD patients not receiving rotigotine.

\subsection{Outcome Parameters}

Patients were assessed during routine clinic visits. Physicians questioned patients about the occurrence of any adverse events. Data were collected in a specific form that was integrated into the patient database, from which other clinical information was extracted. Application site reactions were considered to have occurred when the patient reported dermatitis, itching or erythema. Physician questioning was used to determine the occurrence of dizziness and syncope. Depression was assessed using the 4-item Geriatric Depression Scale, and the Scales for Outcomes in PD-Sleep Scale (SCOPA SLEEP) was used to assess nocturnal sleep and daytime sleepiness. Adverse events considered to be related to rotigotine treatment were recorded and are reported. Adverse events related to other treatments were also recorded but are not reported in this analysis.

To try and identify patient characteristics that might predict the occurrence of adverse events, patients with and without different adverse events were compared for age, dose of rotigotine, dose of levodopa, duration of PD, duration of treatment, and Hoehn \& Yahr score.

\subsection{Statistical Analysis}

Descriptive statistics were used for all data (mean, standard deviation [SD], range). Unpaired Student t or Chi-square tests were used for bivariate comparisons of numerical or categorical variables. Paired Student $t$ test or Wilcoxon signed rank test were used for continuous variables. All analyses were conducted using SPSS 15 software.

\section{Results}

One hundred fourteen patients were included into the study and were followed for 24 months. The mean age was 69.84 years. The Hoehn \& Yahr score is described in table A. At baseline, 33 patients (28.94\%) were receiving 
monotherapy with rotigotine, while the remainder were receiving combination treatment (Table 1). The mean rotigotine dosage was $8.77 \mathrm{mg} /$ day. Carbidopa-levodopa was the most common combination treatment given with rotigotine, followed by rasagiline (Table 1 ).

\section{Adverse Events}

Adverse events by classification are presented in Table 2. No patient experienced dyskinesia. Thirty-nine patients (34.21\%) reported adverse events, twenty-three (20.17\%) of whom had application site reactions. In these patients the rotigotine dosage was 6 - $12 \mathrm{mg} /$ day (mean $8.44 \pm 1.94 \mathrm{mg} /$ day).

Application site reactions led to discontinuation of rotigotine in fourteen patients (12.28\%), while two patients were able to continue treatment when the rotigotine dosage was reduced (to 6 - $8 \mathrm{mg} / \mathrm{day}$ ). Comparing patient characteristics between those who experienced application site reactions with those who did not, the dose of levodopa wasn't have stadistical significance (Table 3). Sixteen patients (14.03\%) presented a systemic adverse event (Table 2), sleep disorders were the most common problem. Treatment was discontinued in eleven patients (9.64\%): as a result of hallucinations in three patients, depression in one patient and dizziness in one patient, syncope in two and impulsive control disorders in two. The dose of rotigotine was $4-12 \mathrm{mg} /$ day in patients who experienced any systemic adverse event, and $4-8 \mathrm{mg} /$ day in those with hallucinations. In patients with depression, dizziness, sleep disorders or syncope, the rotigotine dosage was 6, 8, 8 and $12 \mathrm{mg} /$ day, respectively.

Table 1. Baseline patient characteristics.

\begin{tabular}{|c|c|}
\hline \multicolumn{2}{|c|}{ ROTIGOTINE n = 114} \\
\hline \multicolumn{2}{|l|}{ Age (years) } \\
\hline Mean & 69.84 \\
\hline Range & $54-85$ \\
\hline \multicolumn{2}{|l|}{ Sex, n (\%) } \\
\hline Female & $69(60.52 \%)$ \\
\hline Male & 45 (39.47\%) \\
\hline \multicolumn{2}{|l|}{ H \& Y score, n (\%) } \\
\hline I & 45 (39.47) \\
\hline II & $28(24.56)$ \\
\hline III & $32(28.07)$ \\
\hline IV & $11(9.64)$ \\
\hline \multicolumn{2}{|l|}{ Duration of therapy (months) } \\
\hline Mean & 15.38 \\
\hline Range & $1-48$ \\
\hline Monotherapy, n (\%) & 33 (28.94) \\
\hline Combination therapy, n (\%) & $71(62.28)$ \\
\hline Rasagiline & $47(41.22)$ \\
\hline Amantadine & 15 (28.07) \\
\hline Apomorphine & $5(4.38)$ \\
\hline Quetiapine & $4(3.50)$ \\
\hline L-dopa & 59 (51.75) \\
\hline \multicolumn{2}{|l|}{ Daily dose (mg) } \\
\hline Mean (standar deviation) & 8.77 (2.77) \\
\hline
\end{tabular}


Table 2. Adverse events reported during the observation period, by classification.

\begin{tabular}{cc}
\hline Adverse effects $n=114$ & Patients n (\%) \\
Any event & $39(34.21)$ \\
Application site reactions & $23(20.17)$ \\
Systemic events & $16(14.03)$ \\
Hallucinations & $3(2.63)$ \\
Depression & $1(0.87)$ \\
Dizziness & $1(0.87)$ \\
Syncope & $2(1.75)$ \\
Sleep disorders & $4(3.50)$ \\
Agitation & $2(1.75)$ \\
Impulsive control disorders & $2(1.75)$ \\
\hline
\end{tabular}

Table 3. Patient characteristics that between those who reported specific adverse events and those who did not.

\begin{tabular}{ccccc}
\hline$p$ value & H \& Y score & L-dopa (dose) & Rasagiline & Amantadine \\
\hline Application site reaction & 0.319 & 0.881 & 0.413 & 0.162 \\
Systemic events & 0.291 & 0.687 & 0.396 & $0.002^{*}$ \\
\hline
\end{tabular}

Comparing patient characteristics between those who experienced systemic adverse events with those who did not, the Hoehn \& Yahr score was sligthly higher among those who experienced a systemic event but without stadistical significance (Table 3).

The frequency of adverse events was not significantly affected by the choice of concomitant anti-PD agent, with the exception of amantadine; the incidence of systemic adverse events was significantly lower in patients receiving rotigotine + amantadine versus rotigotine alone $(p=0.002)$. Further analysis revealed that the dosage of levodopa was significantly higher in amantadine recipients who did versus did not have a systemic adverse event (889.58 $\pm 397.29 \mathrm{mg} /$ day vs. $428.13 \pm 390.11 \mathrm{mg} /$ day; $p=0.001$ [Chi-squared test]). Rotigotine dosage was similar in these two patient groups ( $9 \pm 3.77 \mathrm{vs} .8 .70 \pm 2.46 \mathrm{mg} /$ day $)$.

\section{Discussion}

In this group of patients with PD being treated in routine clinical practice, treatment-emergent adverse events were consistent with those expected for nonergoline dopamine receptor antagonists. The incidence of rotigotine-induced adverse events was $34.21 \%$, with systemic side effects and application site reactions reported in $14.03 \%$ and $20.17 \%$ of patients, respectively.

Data from randomized, placebo-controlled trials confirm that transdermal rotigotine is generally well tolerated [9]-[14], regardless of patient age or disease stage [15]. The most commonly reported rotigotine adverse events in patients with early PD were nausea, dizziness, somnolence, insomnia and vomiting [10] [11]. When used in combination with levodopa in patients with advanced PD, the most frequent dopaminergic adverse events in the three randomized, controlled clinical trials were nausea, dizziness and dyskinesia [9] [13] [14]. Dopaminergic adverse events during the use of rotigotine in routine clinical practice included hallucinations, depression, dizziness, syncope and sleep disorders. The frequency of these was comparatively low. For example, the incidence of dizziness in controlled trials was 14\% - 24\% and 6\% - 19\% in patients with early [10] [11] and advanced [9] [13] [14] PD, respectively, compared with $0.87 \%$ in the current study. Dyskinesia was not observed at all in our study; this was possibly attributable to the stable plasma levels of rotigotine.

In all randomized controlled trials, application site reactions were the most common non-dopaminergic adverse events in rotigotine recipients [9]-[14]. The incidence of application site reactions in a long-term open-label extension of two randomized controlled trials [12] [16] in early-stage PD was 11.7\% [7], which is slightly lower 
than the $20.17 \%$ reported in the current study. In the open label extension trial the median duration of rotigotine therapy was approximately 5 years 3 months (longer than the 24 months of follow-up in the current study) and the mean rotigotine dosage at the end of treatment was $7.2 \mathrm{mg} /$ day. The rate of discontinuation due to application site reactions was lower in the extension study (3\%) [7], and in randomized controlled trials (1\% - 8\%) [9] [11]-[14] [16] compared with this study (6.14\%). In both the extension study [7] and the current analysis, the incidence of application site reactions was lower at higher rotigotine dosages. Overall, application site reactions were generally mild to moderate in severity and tend not to limit the use of transdermal rotigotine patches. Daily rotation of the application site is recommended [3], and a topical anti-inflammatory cream can be used if necessary [17]. Two impulse control disorders were encountered in the current study, as it has been reported previously in small numbers of patients. A recent study was seen that ICD was significantly associated with the use of the nonergolinic oral DA (pramipexole and ropinirole) when compared with transdermal non-ergolinic DA (rotigotine) [4] [14] [18] [19].

In other trials with rotigotine conducted in the clinical practice setting [20] [21], the incidence of application site reactions was lower than in the current study, at $2.2 \%$ - 3.7\% compared with $17.3 \%$. Consistent with this study, dizziness was one of the most common systemic adverse events (at similar incidences of $1 \%-3.5 \%$ ), and all events were usually of mild-to-moderate severity. In open-label trials of rotigotine, reported incidences of application site reactions ranged from $6 \%$ to $30 \%$ [22]-[25], putting the $20.17 \%$ seen in the current study in about the middle of the range. The most commonly reported systemic adverse event in the open-label trials was nausea, with an incidence of $9 \%$ - 15\% [22]-[25]. The majority of adverse events were rated as mild-to-moderate.

A number of significant associations between different adverse events and patient factors or concomitant medications were identified in the present study, the Hoehn \& Yahr score was sligty higher in patients with versus without a systemic adverse event, and the incidence of systemic adverse events was lower in patients receiving rotigotine + amantadine versus rotigotine alone. This is potentially explained by the anticholinergic effects of amantadine, which may help avoid systemic adverse events. In addition, the dosage of levodopa was higher in amantadine recipients who did versus did not experience a systemic adverse event. Although patient numbers were small and the standard deviations large, all these comparisons reached statistical significance. To our knowledge these relationships have not previously been described, and therefore deserve attention in future clinical trials.

This study has an observational design and therefore has all the limitations associated with uncontrolled trials. In particular, therapy decisions were made at the discretion of each treating physician and the ability to collect data was limited to that available in medical records and through discussion with patients, which was not necessarily undertaken by the same physician at each visit. The number of patients available at a single centre was quite small, and the patients and their management were relatively heterogeneous. However, data on the use of medications in routine clinical practice provide important information to add to results generated under the stringent conditions of randomized controlled clinical trials.

\section{Conclusion}

The efficacy and tolerability of transdermal rotigotine therapy have been well established in a variety of controlled clinical trials and observational studies. The current findings extend data on the safety and tolerability of rotigotine to routine clinical practice.

\section{References}

[1] Lang, A.E. and Obeso, J.A. (2004) Challenges in Parkinson's Disease: Restoration of the Nigrostriatal Dopamine System Is Not Enough. The Lancet Neurology, 3, 309-316. http://dx.doi.org/10.1016/S1474-4422(04)00740-9

[2] Silver, D. (2006) Impact of Functional Age on the Use of Dopamine Agonists in Patients with Parkinson Disease. Neurologist, 12, 214-223. http://dx.doi.org/10.1097/01.nrl.0000215782.78763.fa

[3] European Medicines Agency (2012) Neupro $2 \mathrm{mg} / 24 \mathrm{~h}$ transdermal Patch: Summary of Product Characteristics [Online].

http://www.emea.europa.eu/2012docs/en_GB/document_library/EPAR___Product_Information/human/000626/WC50 0026397.pdf

[4] Giladi, N., Surmann, E. and Boroojerdi, B. (2011) The Safety and Efficacy of Transdermal Rotigotine over a 6-Year Period in Patients with Early-Stage Idiopathic Parkinson's Disease: SP716 Study Group. Movement Disorders, 26, 
128-129.

[5] LeWitt, P.A., Boroojerdi, B., Poewe, W., et al. (2010) Long-Term Treatment of Advanced Parkinsons Disease with Rotigotine. Neurology, 74, A350. [Abstract]

[6] Watts, R.L., Boroojerdi, B. and Jankovic, J. (2010) Open-Label Extension Trial Assessing the Effects of Long-Term Treatment with Rotigotine in Subjects with Early-Stage, Idiopathic Parkinson's Disease: Results from up to 7 Years. Movement Disorders, 25, S310-S311. [Abstract No. 386]

[7] Elmer, L.W., Surmann, E., Boroojerdi, B., et al. (2012) Long-Term Safety and Tolerability of Rotigotine Transdermal System in Patients with Early-Stage Idiopathic Parkinson's Disease: A Prospective, Open-Label Extension Study. Parkinsonism \& Related Disorders, 18, 488-493. http://dx.doi.org/10.1016/j.parkreldis.2012.01.008

[8] Gelb, D.J., Oliver, E. and Gilman, S. (1999) Diagnostic Criteria for Parkinson Disease. Archives of Neurology, 56, 33-39. http://dx.doi.org/10.1001/archneur.56.1.33

[9] LeWitt, P.A., Lyons, K.E. and Pahwa, R. (2007) Advanced Parkinson Disease Treated with Rotigotine Transdermal System: PREFER Study. Neurology, 68, 1262-1267. http://dx.doi.org/10.1212/01.wnl.0000259516.61938.bb

[10] Giladi, N., Boroojerdi, B., Korczyn, A.D., et al. (2007) Rotigotine Transdermal Patch in Early Parkinson's Disease: A Randomized, Double-Blind, Controlled Study versus Placebo and Ropinirole. Movement Disorders, 22, 2398-2404. http://dx.doi.org/10.1002/mds.21741

[11] The Parkinson Study Group (2003) A Controlled Trial of Rotigotine Monotherapy in Early Parkinson's Disease. Archives of Neurology, 60, 1721-1728. http://dx.doi.org/10.1001/archneur.60.12.1721

[12] Watts, R.L., Jankovic, J., Waters, C., Rajput, A., Boroojerdi, B. and Rao, J. (2007) Randomized, Blind, Controlled Trial of Transdermal Rotigotine in Early Parkinson Disease. Neurology, 68, 272-276. http://dx.doi.org/10.1212/01.wnl.0000252355.79284.22

[13] Poewe, W.H., Rascol, O., Quinn, N., Tolosa, E., Oertel, W.H., Martignoni, E., et al. (2007) Efficacy of Pramipexole and Transdermal Rotigotine in Advanced Parkinson's Disease: A Double-Blind, Double-Dummy, Randomised Controlled Trial. The Lancet Neurology, 6, 513-520. http://dx.doi.org/10.1016/S1474-4422(07)70108-4

[14] Trenkwalder, C., Kies, B., Rudzinska, M., Fine, J., Nikl, J., Honczarenko, K., et al. (2011) Rotigotine Effects on Early Morning Motor Function and Sleep in Parkinson's Disease: A Double-Blind, Randomized, Placebo-Controlled Study (RECOVER). Movement Disorders, 26, 90-99. http://dx.doi.org/10.1002/mds.23441

[15] Ghys, L., LeWitt, P.A., Grieger, F., et al. (2010) Treatment of Patients with Early and Advanced Parkinson's Disease (PD) with Transdermal Rotigotine: Age Relationship to Safety and Tolerability. Proceedings of the 7th International Congress on Mental Dysfunctions and Other Non-Motor Features in Parkinson's Disease and Related Disorders, Barcelona, 9-12 December 2010, Abstract.

[16] Jankovic, J., Watts, R.L., Martin, W. and Boroojerdi, B. (2007) Transdermal Rotigotine: Double-Blind, PlaceboControlled Trial in Parkinson Disease. Archives of Neurology, 64, 676-682. http://dx.doi.org/10.1001/archneur.64.5.676

[17] Chen, J.J., Swope, D.M., Dashtipour, K. and Lyons, K.E. (2009) Transdermal Rotigotine: A Clinically Innovative Dopamine-Receptor Agonist for the Management of Parkinson's Disease. Pharmacotherapy, 29, 1452-1467. http://dx.doi.org/10.1592/phco.29.12.1452

[18] Wingo, T.S., Evatt, M., Scott, B., Freeman, A. and Stacy, M. (2009) Impulse Control Disorders Arising in 3 Patients Treated with Rotigotine. Clinical Neuropharmacology, 32, 59-62. http://dx.doi.org/10.1097/WNF.0b013e3181684542

[19] Garcia-Ruiz, P.J., Martinez Castrillo, J.C., Alonso-Canovas, A., Herranz Barcenas, A., Vela, L., Sanchez Alonso, P., Mata, M., Olmedilla Gonzalez, N. and Mahillo Fernandez, I. (2014) Impulse Control Disorder in Patients with Parkinson's Disease under Dopamine Agonist Therapy: A Multicentre Study. Journal of Neurology, Neurosurgery, and Psychiatry, 85, 840-844.

[20] Ceballos-Baumann, A. and Hack, H.J. (2011) Rotigotine Transdermal Patch in Combination Therapy for Parkinson’s Disease-Observations in Routine Clinical Practice. Current Medical Research and Opinion, 27, 1899-1905. http://dx.doi.org/10.1185/03007995.2011.611630

[21] Schnitzler, A., Leffers, K.W. and Hack, H.J. (2010) High Compliance with Rotigotine Transdermal Patch in the Treatment of Idiopathic Parkinson's Disease. Parkinsonism \& Related Disorders, 16, 513-516. http://dx.doi.org/10.1016/j.parkreldis.2010.06.009

[22] Babic, T., Boothmann, B., Polivka, J., Rektor, I., Boroojerdi, B., Häck, H.-J. and Randerath, O. (2006) Rotigotine Transdermal Patch Enables Rapid Titration to Effective Doses in Advanced-Stage Idiopathic Parkinson Disease: Subanalysis of a Parallel Group, Open-Label, Dose-Escalation Study. Clinical Neuropharmacology, 29, $238-242$. http://dx.doi.org/10.1097/01.WNF.0000228179.83335.65

[23] Giladi, N., Fichtner, A., Poewe, W. and Boroojerdi, B. (2010) Rotigotine Transdermal System for Control of Early Morning Motor Impairment and Sleep Disturbances in Patients with Parkinson's Disease. Journal of Neural Trans- 
mission, 117, 1395-1399. http://dx.doi.org/10.1007/s00702-010-0506-4

[24] Guldenpfennig, W.M., Poole, K.H., Sommerville, K.W. and Boroojerdi, B. (2005) Safety, Tolerability, and Efficacy of Continuous Transdermal Dopaminergic Stimulation with Rotigotine Patch in Early-Stage Idiopathic Parkinson Disease. Clinical Neuropharmacology, 28, 106-110. http://dx.doi.org/10.1097/01.wnf.0000162228.00154.ba

[25] Rektor, I., Babic, T., Boothmann, B., Polivka, J., Boroojerdi, B. and Randerath, O. (2009) High Doses of Rotigotine Transdermal Patch: Results of an Open-Label, Dose-Escalation Trial in Patients with Advanced-Stage, Idiopathic Parkinson Disease. Clinical Neuropharmacology, 32, 193-198. http://dx.doi.org/10.1097/WNF.0b013e31819a689f 
Scientific Research Publishing (SCIRP) is one of the largest Open Access journal publishers. It is currently publishing more than 200 open access, online, peer-reviewed journals covering a wide range of academic disciplines. SCIRP serves the worldwide academic communities and contributes to the progress and application of science with its publication.

Other selected journals from SCIRP are listed as below. Submit your manuscript to us via either submit@scirp.org or Online Submission Portal.
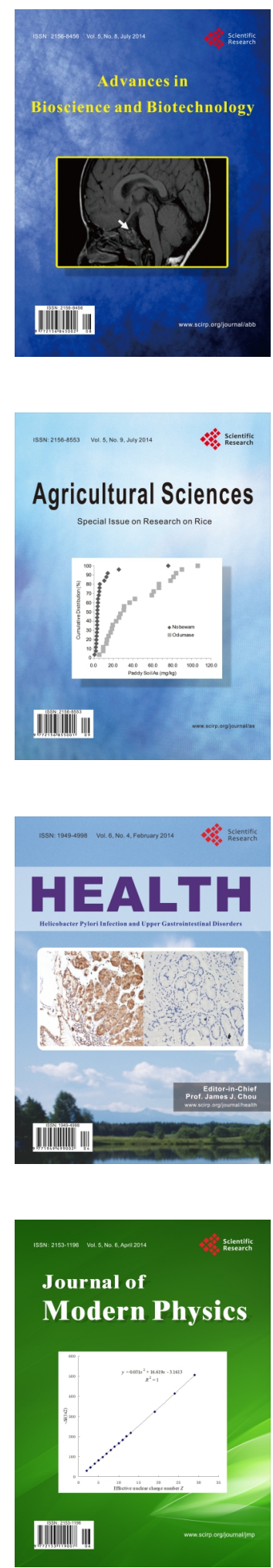
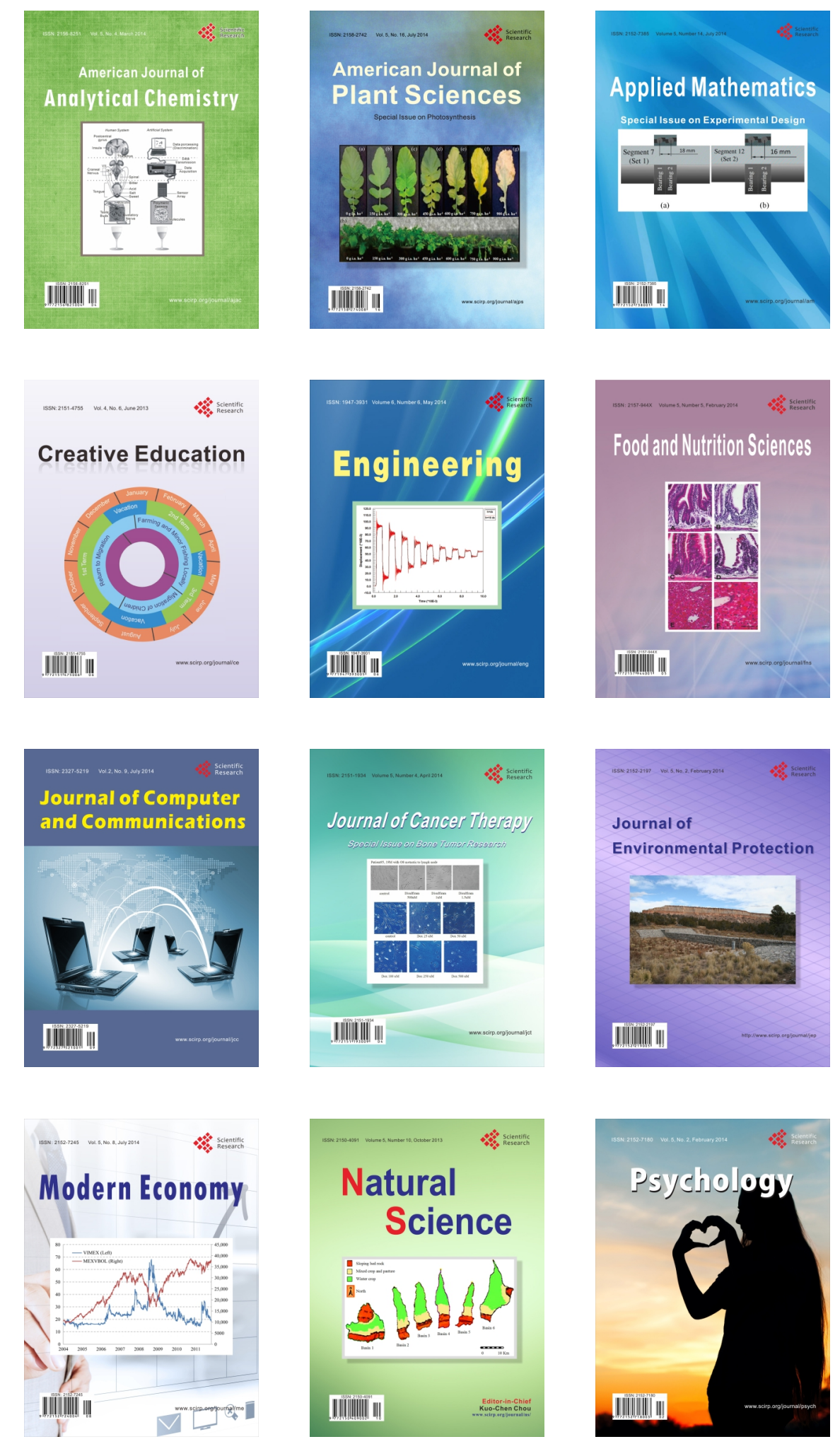